\title{
Entre laços: representação e identidade racial num livro didático de espanhol
}

\section{Among Laces: Representation and racial identity in a course book for spanish teaching}

\section{Ione da Silva JOVINO* \\ UEPG \\ Ligia Paula COUTO** \\ $U E P G$}

Resumo: Este artigo apresenta a parte final de uma pesquisa sobre uma coleção de livros didáticos de espanhol, mais especificamente a Coleção Enlaces, e sua relação com as questões de diversidade sociocultural e de identidade étnico-racial. Para tanto, contextualiza a pesquisa, sua ligação com um projeto de ensino de línguas na perspectiva das africanidades e situa sua relevância a partir de breve revisão sobre o tema. A análise traz aspectos qualitativos e quantitativos e utiliza referenciais principalmente das ciências sociais e, em especial, dos estudos culturais. A pesquisa foi feita em três fases, sendo apresentada aqui a terceira. Ressaltam-se os dados obtidos nas duas primeiras etapas, com análise das imagens, contemplando os principais resultados, tanto em termos numéricos quanto no plano mais simbólico, da representação da identidade racial negra. Em seguida apresenta análise referente ao terceiro recorte, que prioriza uma unidade didática do terceiro volume da coleção, observando todos os textos e conteúdos das atividades em relação à tematização da vida social e da representação da identidade racial. Finaliza apontando como destaque a escolha dos textos da unidade analisada, o caráter inovador e de suporte positivo às discussões sobre identidade das atividades. Ressalta ainda as mudanças nos critérios de avaliação do PNLD e o protagonismo da militância negra.

Palavras-chave: Livro didático. Representação. Identidade racial. Negros

\begin{abstract}
This article presents the final part of a study of a collection of course books for Spanish teaching entitled Coleção Enlaces and its relationship to the themes of social-cultural diversity and ethnic-racial identity. The article presents the research, its connection to a language teaching project based on an African perspective, and shows its relevance by reviewing the topic briefly. The analysis has both qualitative and quantitative aspects and uses references from the social sciences, especially from the field of cultural studies. The research was developed in three stages and this article discusses the third stage. The data from the first two stages are discussed and images are analyzed, focusing on the most important results, in terms of numbers and also in terms of symbolism, of the black racial identity that is represented. Subsequently, the analysis related to the third stage of the research is presented, which focuses on a didactic unit of the third volume of these books, observing all the texts and contents of the activities related to
\end{abstract}

\author{
* Professora do \\ Mestrado em \\ Linguagem, \\ Identidade e \\ Subjetividade e \\ do Departamento \\ de Estudos da \\ Linguagem $\mathrm{Na}$ \\ Universidade \\ Estadual de Ponta \\ Grossa (UEPG). \\ ionejovino@gmail. \\ com. \\ ** Professora do \\ Departamento \\ de Estudos da \\ Linguagem $\mathrm{Na}$ \\ Universidade \\ Estadual de Ponta \\ Grossa (UEPG). \\ ligiapaula@yahoo. \\ com
}


the theme of social life and the representation of racial identity. We conclude by highlighting the selection of texts in this didactic unit, its innovative aspects and the positive support that it provides regarding the discussion of identity in the activities. We also discuss the changes in the evaluation criteria of the PNLD and the protagonism of black militant action.

Keywords: Course books. Representation. Racial identity. Black people.

\section{Antes do laço: contornos e contextos}

Este artigo apresenta a parte final de uma pesquisa sobre uma coleção de livros didáticos (LDs) de espanhol, mais especificamente a Coleção Enlaces (OSMAN et al., 2013), volume 3, e sua relação com as questões de diversidade sociocultural e linguística e de identidade étnico-racial. Nossas preocupações com o livro didático (LD) se iniciaram desde nossa atuação no Programa Institucional de Bolsas de Iniciação à Docência (PIBID). O projeto PIBID é um programa da Coordenação de Aperfeiçoamento Pessoal de Nível Superior (CAPES) que auxilia na formação inicial e continuada dos bolsistas e/ou docentes e, no caso do projeto de Espanhol/Português no qual atuamos desde 2011, desenvolvido na Universidade Estadual de Ponta Grossa, visa desenvolver um trabalho apoiado na teoria dos gêneros textuais no ensino de línguas, considerando a perspectiva da abordagem das africanidades e as contribuições da cultura africana. Além disso, o referido projeto PIBID também atua na produção e análise de LDs com as mesmas diretrizes.

Para conseguirmos abordar o LD de espanhol em sua relação com tais questões, precisamos problematizar a inserção da língua espanhola na grade curricular do Ensino Médio (EM), o crescimento de publicações de LD para o ensino de espanhol neste nível de ensino e a importância que os aspectos culturais e de identidade étnico-racial ganharam na área de língua estrangeira (LE). Assim, iniciaremos a discussão focando as políticas linguísticas e o mercado editorial para a área de espanhol no EM; em seguida, trataremos de alguns documentos oficiais (PCNEM, OCEM, PCN+, PCN Pluralidade Cultural) e pesquisas que fundamentam o debate acerca das identidades sociais no ensino de línguas e, por último, analisaremos a unidade didática (UD) 6 de Enlaces (OSMAN et al., 2013), volume 3, para verificar como a identidade étnico-racial e a diversidade sociocultural e linguística são aí trabalhadas.

A fundação do Mercado Comum do Sul (Mercosul), processo de integração regional iniciado em 26 de março de 1991, com a assinatura do Tratado de Assunção pelos governos da Argentina, Brasil, Paraguai e Uruguai, visando primordialmente uma integração econômica dos respectivos 
países, alavancou o interesse por aprender espanhol no contexto brasileiro. Assim, nos anos 1990 houve um crescimento considerável de turmas de espanhol em escolas de idiomas e, consequentemente, uma necessidade maior de acesso a materiais didáticos variados para o ensino deste idioma.

As políticas linguísticas para a inserção do espanhol no EM começam a ser mais debatidas, principalmente a partir da publicação da Lei Federal 11.161, sancionada em 5 de agosto de 2005. Esta Lei tornou o idioma espanhol a única LE obrigatória no EM. No entanto, por estabelecer que a oferta é obrigatória, mas a matrícula é facultativa para o aluno, acabou não promovendo uma revisão da grade curricular para as línguas estrangeiras (LEs) neste nível de ensino, e assim, na maioria dos estados brasileiros, a língua inglesa prevalece no horário regular de aulas.

Apesar de o inglês ser o idioma estrangeiro predominante nas matrizes curriculares de nossas escolas, a Lei 11.161/05 impulsionou a ampliação do ensino de espanhol no Brasil. Com a obrigatoriedade do espanhol no EM, o Programa Nacional do Livro Didático (PNLD) abriu edital para o envio de propostas de LD para esse idioma. Com isso, o mercado editorial, que já havia incrementado a publicação de LD de espanhol principalmente por causa do Mercosul, começa a se voltar para a produção de materiais mais condizentes com os documentos oficiais para a área de espanhol/LE (E/LE). É neste contexto de ampliação do mercado editorial e seleção de LD pelo PNLD, que a Coleção Enlaces obteve aprovação e poderá ser utilizada na escolas públicas brasileiras de 2015 a 2017. É importante ressaltar que, além da Coleção Enlaces, houve somente mais uma coleção aprovada neste edital do PNLD, foi a Cercanía Joven.

É importante olhar atenta e criticamente para os materiais produzidos no PNLD, para se verificar os discursos sobre identidades que estão "sendo veiculados no ambiente escolar, ainda mais na escola pública, onde o acesso à informação é de caráter mais amplo, ou seja, atinge mais uma diversidade de segmentos sociais, culturais e étnico-raciais" (JOVINO, 2014, p. 126). Desde um olhar para a linguística aplicada, Ferreira (2014) assevera que "escrever e pensar sobre livros didáticos de língua estrangeira no Brasil requer refletir de como era e como é atualmente o ensino de língua estrangeira no Brasil até então e qual é o papel do livro didático" (p. 93).

Podemos afirmar que, nos anos 1990, parte dos livros didáticos, ao explorar aspectos culturais, o faziam utilizando estereótipos, quando não, silenciavam sobre a diversidade cultural, apagando a pluralidade de falares e falantes, de temas, etc. Não havia, naquele momento, tantos estudos relacionados às questões culturais e de identidade com uma reflexão crítica acerca do trabalho com a cultura nas aulas de LEs. Além disso, atividades que propusessem um debate sobre as identidades sociais, arriscamos dizer que eram praticamente inexistentes. Com a publicação dos PCNEM 
(2000), PCN+ (2002) e OCEM (2006) e a ampliação de pesquisas sobre a importância da cultura no ensino de LE, outras visões a respeito da relação cultura e língua foram atribuídas ao ensino.

Nas OCEM (2006), por exemplo, os termos linguagem e cultura aparecem juntos em grande parte do documento. Compreender o caráter heterogêneo dos conceitos de linguagem e cultura se mostra imprescindível para a teoria apresentada, uma vez que formam a base da teoria dos letramentos e comunidades de prática. Os PCN+ (2002) apontam, nas sugestões de competências do trabalho pedagógico, que o ensino de línguas deve "lutar contra os preconceitos e as discriminações sexuais, étnicas e sociais” e também que o espaço da aula de LE serve para a “aproximação dos alunos com culturas e modos diferentes de ver o mundo e nele estar, visando a combater estereótipos e preconceitos, propiciando o convívio solidário das diversidades” (p. 133-134).

Considerando ainda a importância da cultura nos processos de ensino/aprendizagem, houve a publicação dos PCN Pluralidade Cultural (1998), como tema transversal. Ainda que pensado para o Ensino Fundamental (EF), este documento trouxe para o debate a questão do combate ao preconceito e à discriminação racial/étnica na escola e na sociedade brasileira, e também da necessidade de conhecer e valorizar as diferentes "características étnicas e culturais dos diferentes grupos sociais que convivem no território nacional” (BRASIL, 1998, p. 121).

Apesar de levarmos em consideração o significado de um documento oficial que torna pública a urgência de a escola brasileira reconhecer e combater preconceitos, concordamos com Gonçalves e Silva (1998, 2003), que fizeram importantes apontamentos sobre os PCN, em especial sobre os temas transversais. Eles observam que se algumas questões de fundo sobre a diversidade cultural e suas conexões com processos democráticos não fossem tratadas com o cuidado necessário, corria-se o risco de se ver a discussão de um tema tão importante transformado em mero arranjo de conteúdos e métodos pedagógicos, fechados no círculo dos especialistas em currículo. Eles assinalam o aspecto "positivo, otimista e até conservador” dos PCN, sendo que seu discurso dava a entender que seria suficiente as práticas escolares reconhecerem no interior da escola as diferenças culturais e automaticamente seus atores respeitariam a diversidade, "uma vez que a sociedade brasileira é pluricultural”. (GONÇALVES; SILVA, 2003, p. 111).

Para esses autores, os debates iniciados pelos e a partir dos PCN não deixavam claro que os problemas sociais causados, por exemplo, pelo racismo, no caso da sociedade brasileira, transformados apenas em temas transversais, não permitiriam ver como os próprios movimentos sociais, multiculturais, pluriétnicos e raciais "punham (e continuam pondo) em questão as sociedades, as noções de direitos individuais e coletivos, o Estado, 
e todas as instituições, inclusive a escola”. O problema seria tratar disso apenas como algo presente nas práticas escolares, transformados em temas transversais ou até em um “caprichoso estilo de vida”. (GONÇALVES; SILVA, 2003, p. 111).

Os autores apresentavam um temor, em seu texto de 1998, de que a academia brasileira não estivesse preparada para discutir e propor pesquisas nos campos do multiculturalismo, da educação multicultural e da diversidade cultural, pois não haveria produção nacional suficiente à época. Porém, esse temor se dissipa no texto de 2003, uma vez que já haveria, pelo menos no campo da educação, pesquisadores/as com produção em revistas de grande circulação e outros meios, como coletâneas. Os programas de pós-graduação também já se abriam para a orientação de trabalhos a partir desta perspectiva teórica. Tantos anos depois dos textos de Gonçalves e Silva (1998, 2003), e passados 12 anos da promulgação da Lei 10.639/2003 e sete da Lei 11.645/2008, não podemos ainda prescindir das observações finais de Gonçalves e Silva (2003, p. 121):

[...] uma lição da qual não podemos nos esquecer é a de que uma educação multicultural exigirá, de nós, um enorme trabalho de desconstrução de categorias. Caso contrário, o tema da pluralidade cultural preconizado pelos Parâmetros Curriculares Nacionais levará muito tempo para chegar às salas de aula, sem deixar de ser tratado com significações que acentuam e atualizam discursos e atitudes preconceituosos e discriminatórios.

Ferreira (2014) aponta que, desde o final da década de 1990, têm sido ampliadas de forma considerável as áreas de pesquisa sobre o LD. A autora destaca o campo da linguística aplicada, como ela se ocupou nos últimos anos do LD de LE como fonte para a discussão acerca das identidades sociais de raça, de gênero, de sexualidade e de classe, e que grande parte das pesquisas sobre o tema são feitas por pesquisadores/as da área no Brasil e no exterior. A autora faz atenta revisão bibliográfica do tema, indicando também relevantes pesquisas brasileiras de outras áreas, como as de Silva (1995); Silva (2005), Negrão (1987), Watthier e Ferreira (2008), e Rosemberg, Bazilli e Silva (2003).

Destacaremos alguns trabalhos que, mesmo não tratando estritamente do LD de LE, podem ser considerados balizadores de grande parte das reflexões realizadas no Brasil sobre o LD. Para tanto, seguiremos a trilha indicada por Ferreira em sua revisão, apresentando síntese de alguns dos trabalhos.

Silva (1995) destaca que as primeiras preocupações em relação ao $\mathrm{LD}$, em termos de pesquisa sobre a questão racial negra, “parecem ter surgido com trabalhos no início da década de 1950” (p. 16). Desde essa época, buscavam-se os impactos que as ideologias de inferiorização de negros e negras e de superioridade de pessoas brancas poderiam ter sobre 
estudantes que utilizavam tais materiais. No contexto de sua pesquisa, a autora destaca que o LD omitia, de modo geral, “o processo histórico e cultural, o cotidiano e as experiências dos segmentos subalternos da sociedade, como o índio, o negro, a mulher, entre outros”. (SILVA, 1995, p. 47). Em relação aos negros, ela ressalta sua ausência ou a representação carregada de estereotipa negativa. Os estereótipos revelariam de forma explícita os discursos de inferiorização e desumanização do negro, bem como sua representação imagética de forma "caricaturada, deformada, associado a seres destrutivos e sujos”, associado a animais (SILVA, 1995, p. 51). Cabe demarcar que a autora analisou LDs de “comunicação e expressão” dirigidos ao que chamaríamos hoje de séries inicias do primeiro ciclo do EF.

Silva (2005) apresentou a análise do discurso sobre segmentos raciais negros e brancos nos LD de língua portuguesa produzidos no período de 1975 a 2004. O autor ponderou as permanências e mudanças da produção do discurso racista, seguindo uma perspectiva diacrônica, verificando a existência de um aumento na exposição de personagens negros no LD, entretanto eles permaneceriam dados a ver em situação de miséria, enquanto os brancos continuariam mais valorizados, significando a representação da espécie humana, situação que resultaria em desigualdade.

Rosemberg, Bazilli e Silva (2003) fizeram ampla revisão de literatura, buscando mostrar de que forma o racismo e seu combate apareciam nos materiais didáticos brasileiros, com base em pesquisas e estudos publicados sobre o tema, num período de 50 anos. Naquele momento, os autores consideravam a "produção brasileira de pesquisas sobre livros didáticos em geral [...] e sobre o racismo em livros didáticos, em especial” como sendo "reduzida e incipiente” (p. 127). Ponderavam também, dentre muitas outras questões, que as pesquisas preocupadas com os discursos racistas faziam referência exclusivamente a negros e indígenas, nunca a outros grupos étnico-raciais. Outro relevante apontamento é de que até o início dos anos 2000, praticamente inexistiam trabalhos sobre LDs que não fossem de história ou língua portuguesa.

Barros e Santos (2012), num artigo sobre a questão da construção das identidades sociais construídas no/pelo LD de espanhol, verificaram que ideologias ou questões hegemônicas marcam a representação das identidades sociais no material analisado, postulando que as mesmas exercem influência sobre a construção das identidades sociais dos alunos. Os autores perceberam as concepções de identidade de raça, gênero e classe contidas, conduzidos pelo aporte teórico-metodológico da Análise Crítica do Discurso e dos Estudos Culturais, demonstrando que o LD analisado trazia representações cristalizadas da alteridade, reforçando estereótipos culturais. 
Assim, é muito recente a produção que vem tematizando a vida social, investigando e divulgando, tendo como base o LD de LE. Destaquem-se as coletâneas organizadas por Scheyerl e Siqueira (2012), e por Ferreira (2012). No projeto PIBID, mencionado inicialmente, temos trazido à tona tais discussões a partir dos aspectos culturais, selecionando como ponto de partida o conceito de africanidades no ensino de E/LE, conforme se pode conferir em Couto, Jovino, Maciel e Nunes (2012), Jovino (2012), Jovino, Couto et al (2012), Couto, Jovino e Maciel (2013), dentre outros. A pesquisa específica sobre a Coleção Enlaces foi iniciada em 2012 e os resultados parciais foram publicados em Jovino (2013) e Jovino $2014^{1}$.

\section{Enlaçamento}

As duas etapas anteriores da pesquisa com a Coleção Enlaces centraram-se na análise da representação de negros por meio das imagens, em especial das fotografias que apareciam nos LDs. Em Jovino (2013), destacamos a análise de uma unidade da coleção disponibilizada no site da editora na internet. Os resultados apontavam para:

[...] uma diversidade de representação de pessoas negras. As imagens de crianças, jovens e adultos negros, muitas vezes, estão em primeiro plano. Além disso, os negros são apresentados inseridos em diferentes contextos (escolares e sociais), juntamente com outros grupos étnico-raciais. [...] Quando o negro é representado em relações familiares (pai e filho), são relações afetivas.

[...] O discurso imagético presente no LD colabora para a desconstrução do estereótipo de que negro somente exerce profissões de menor poder ou status na escala social como, por exemplo, empregadas domésticas ou trabalhadores braçais, porque duas imagens retratam dois adultos negros atuando como professores.

[...] A expressão facial dos personagens negros presentes traz um sorriso, expressões variadas de alegria, afastando a ideia estereotipada de sofrimento ligada às questões históricas do período de escravidão e tão recorrentemente recuperada no cenário social. Ademais, os negros não são apresentados apenas em representações artísticas, tais como o hip-hop. Por fim, quando trata do tema moda, apresenta modelos negros e diferentes estilos. (JOVINO, 2013, p. 8).

Os principais fatores considerados para análise dos resultados foram as diversas abordagens da figura dos negros(as) e sua possível repercussão na sociedade. Os primeiros resultados apontaram para imagens distanciadas de estereótipos marcadamente expressos na cultura brasileira.

Em continuidade à pesquisa, foi analisada a versão do ano de 2010 da Coleção Enlaces (OSMAN et al., 2010). Foram analisadas novamente as fotografias, dos três volumes, buscando:

\author{
${ }^{1} \mathrm{O}$ trabalho \\ desenvolvido engloba \\ pesquisa sobre \\ representação de \\ negros e negras, cujas \\ fontes, além do LD \\ de espanhol, também \\ incluem a literatura \\ dirigida ao público \\ infantil e juvenil \\ e à publicidade. \\ Este conjunto de \\ atividades, também \\ parte do Projeto de \\ Pesquisa "Discurso \\ e Relações Raciais”, \\ realizado em conjunto \\ e coordenado \\ pelo NEAB da \\ Universidade Federal \\ do Paraná, com \\ apoio da Fundação \\ Araucária.
}


[...] a representação de negros e negras, com base inicialmente nas imagens, mais particularmente a fotografia, que pode ser entendida dentro de uma análise da mensagem visual fixa, a qual como o quadro, o cartaz, o mapa, a maquete, a planta de construção podem caracterizar a representação do que se almeja retratar. (JOVINO, 2014, p. 125-126).

Na análise, foram observados os três volumes da coleção, olhando-se as imagens que pudessem ser classificadas como fotografias e nas quais se pudessem visualizar pessoas e identificar sua cor/raça. Para Guimarães (2008), a articulação entre cor e raça seria necessária porque cor "não é uma categoria objetiva, cor é uma categoria racial, pois quando se classificam as pessoas como negros, mulatos ou pardos é a ideia de raça que orienta essa forma de classificação” (p. 76). Pensamos a identidade por meio da fotografia por ela ser também uma representação, posto que passa por escolhas, processos que decidem o resultado. É também uma representação da representação, pois há que se considerar todo o processo que envolve a escolha e seleção das imagens para fazerem parte do LD (cortes, vetos, trocas, etc. que envolvem o processo de editoração e revisão).

Quanto aos aspectos qualitativos, resumidamente se pode dizer que encontramos 312 imagens de pessoas brancas para 89 de pessoas negras. No recorte por gênero, observam-se 152 homens brancos para 33 homens negros e 127 mulheres brancas para 56 mulheres negras.

Os aspectos qualitativos da análise deixaram perceber questões tanto positivas quanto negativas. Por exemplo, na representação de profissões, os negros e negras não aparecem atuando em profissões socialmente desprestigiadas como o trabalho doméstico, contudo também não são representados como executivos ou médicos. Este espaço é reservado somente aos brancos. Há imagens de dois homens negros, um mecânico e outro professor, e uma mulher negra como professora. Outro espaço reservado quase que exclusivamente aos brancos, e do sexo masculino, é dos esportes. No caso dos homens negros cabe o estereótipo clássico do futebol. No primeiro volume, em aproximadamente 10 páginas sobre esportes, contabilizamos imagens de 20 atletas de outros esportes que não o futebol, e praticamente todos são homens e brancos.

A representação de grupos de pessoas negras propriamente inexiste nos três volumes da coleção, exceto quando o assunto é futebol. Nesse caso, mostram-se fotos de seleções brasileiras com a quase totalidade de jogadores negros. Outra exceção são duas imagens de famílias negras, sendo que uma delas acompanha uma atividade com verbete no qual consta a definição de família. Outra imagem para um grupo familiar com traços indígenas. Uma grande imagem na abertura de uma unidade tem um grupo de estudantes negros.

Voltando à questão do futebol, um estereótipo dito clássico de representação do negro, este é o único caso em que aparecem brasileiros 
com identificação de nome. Somente dois casos se diferenciam, um deles é a imagem do presidente norte-americano Barack Obama, que aparece em mais de um volume, e o outra, a de Milton Santos, que aparece numa atividade para discussão dos efeitos da globalização, com duas citações de textos dele, apresentado como premiado geógrafo.

Quase não há crianças nas imagens da coleção, explicável talvez pelo público alvo do livro, estudantes de EM. Entretanto, uma fotografia do volume 3 merece destaque por apresentar um menino negro caracterizado como cientista; tal positividade, senão numérica, tem valor simbólico considerável. (JOVINO, 2014).

Ao falar de estereótipo, é importante explicitar que o temos visto como uma forma de representação de identidades. Ele permite, por um lado, observar a fixação de grupos em posições cristalizadas, analisar as diferenças vistas como critério para inferiorização. Por outro lado, possibilita apontar o rompimento de padrões hegemônicos de representação, a partir de imagens (e conteúdos outros) que começam a aparecer, de modo a romper com um padrão hegemônico, cristalizado ou inferiorizante de representação.

Uma prática representacional, como é o caso do estereótipo, tenta fixar os significados, escolhendo um único e apagando os demais. Há duas estratégias frequentemente usadas: (1) a naturalização, que objetiva fixar a diferença e evitar que o significado "deslize” (HALL, 1997); e (2) a separação, isto é, a demarcação de fronteiras e exclusão do que não pertence (prática de fechamento e exclusão).

\section{Enlaces: do mesmo, só que mais}

No tocante à versão atual da Coleção Enlaces, integrante do PNLD 2013, na apresentação do material aos alunos, as autoras afirmam a importância de conhecer a língua e a cultura do outro. Elas também mencionam a questão da identidade e de nossa proximidade com o mundo hispânico, esclarecendo que as atividades com aspectos culturais contemplarão os países hispânicos e, ao mesmo tempo, o Brasil. O ensino do espanhol é explicado como um ensino que pode contribuir para a formação geral e cidadã desses alunos, com a utilização de variados gêneros das diversas culturas de língua espanhola. Por fim, as autoras concluem:

Nuestra intención es contribuir, a través del español, en el campo del lenguaje, con el desarrollo de tus habilidades y competencias, de modo que, conociendo tus derechos y deberes, puedas convivir con las diferencias, de forma respetuosa, en sus más variadas manifestaciones; así como actuar de forma efectiva y transformadora en el medio donde vives. (OSMAN et al., 2013, volume 3, p. 3). 
Como podemos verificar, nesta apresentação do $\mathrm{LD}$, as autoras não se distanciam das propostas dos documentos oficiais referidos anteriormente. Pelo contrário, reforçam a necessidade de se conviver com as diferenças, em suas mais variadas manifestações, de maneira respeitosa.

Além disso, na parte do LD em que se explica como cada unidade está dividida e como funciona o apêndice, podemos constatar uma seção que aborda especificamente a temática cultural. Esta seção está intitulada Nos... otros.

El foco de esta sección son las relaciones interculturales; encontrarás actividades de los más diferentes tipos para trabajar relaciones de acercamiento y lejanía entre las culturas de los hispanohablantes y los brasileños. (OSMAN et al., 2013, vol. 3, p. 5).

Neste momento, o conceito "intercultural" aparece. Paraquett (2010), apoiada em García Martínez et al. (2007), esclarece o conceito de interculturalidade e sua relação com as aulas de espanhol. Assim como Candau (2009), ela destaca o caráter dialógico de tal conceito, uma vez que o prefixo “inter” representaria “a integração, o encontro, o diálogo" (PARAQUETT, 2010, p. 146). Essa integração, encontro e diálogo com as mais variadas culturas estrangeiras objetivaria uma formação de alunos e professores para o reconhecimento das diferenças, desenvolvimento de valores democráticos e responsabilidade ética e política. Essa formação, portanto, caminharia na direção de superação de preconceitos e estereótipos relacionados às culturas dos países falantes de espanhol. E ainda, segundo Paraquett (2010), esse trabalho com as culturas estrangeiras seria uma forma de o estudante refletir sobre cultura de maneira geral e "intensificar o seu processo de pertencimento cultural ao ambiente no qual vive” (p. 143).

Mais uma vez, verificamos que a Coleção Enlaces parece objetivar uma superação dos estereótipos e um trabalho com aspectos culturais que consideram a diversidade e o diálogo entre as diferentes culturas, de modo a contribuir para a formação de um aluno que seja mais sensível às diferenças e mais respeitoso com o outro.

Algo interessante de se notar é que, no índice de todos os volumes deste LD, há uma preocupação em trazer, além das informações mais básicas sobre cada unidade, as competências e habilidades, as funções comunicativas, os gêneros discursivos, o tema transversal e o aspecto interdisciplinar que serão trabalhados. Ou seja, isso seria uma indicação de que o ensino de espanhol passa a ser compreendido para além da mera comunicação e estudo e prática de estruturas ideais.

A seguir, trataremos das questões raciais na Coleção Enlaces, mas antes disso faz-se necessário apresentar minimamente as perspectivas teóricas que nos orientam ao falar de raça, racismo e identidade étnico-racial. Concordando com Munanga (2003) e Guimarães (2002, 2008), partimos 
do pressuposto da inexistência de raça no sentido biológico, todavia fazemos a ressalva de que raça seja um conceito político, social e historicamente construído.

[...] "raça” não é apenas uma categoria política necessária para organizar a resistência ao racismo no Brasil, mas também é uma categoria analítica indispensável: a única que revela que as discriminações e desigualdades que a noção brasileira de "cor” enseja são efetivamente racistas e não apenas de “classe”. (GUIMARÃES, 2002, p. 50).

Para Guimarães (2008), as raças são, cientificamente, uma construção social e devem ser estudadas por um ramo próprio da sociologia ou das ciências sociais, que trata das identidades sociais, estando, portanto, situada no campo da cultura, e da cultura simbólica. Assim, podemos também entender a identidade de raça como algo construído social, histórica, política e discursivamente. Do ponto de vista dos estudos culturais, também é importante falar de um aspecto que diz respeito às identidades, que diz respeito à representação. Entenda-se por representação, neste ponto, um sistema de significação ou atribuição de significado a pessoas e coisas por meio da linguagem, cultural e socialmente construídos. Pessoas e objetos não detêm em si um significado fixo, final ou verdadeiro (HALL, 1997). Introduzimos representação aqui, pois as identidades têm que ser representadas, são significadas por meio da representação. (WOODWARD, 2000).

Como a identidade está no plano simbólico e também se relaciona com a produção de cultura, Munanga (2003) alerta que é preciso “entender o conteúdo político ou ideológico de expressões como “identidade racial negra', ‘identidade étnica negra’, ou 'identidade étnico-racial negra’” evitando pensar que "os negros produzem cultura e identidade negras como as laranjeiras produzem laranjas e as mangueiras mangas.” (p. 33).

Para Guimarães (2002, p. 51), ainda é possível falar de raça porque existem identidades raciais, ou seja, os grupos sociais que se identificam "a partir de marcadores direta ou indiretamente derivados da ideia de raça"; porque as desigualdades, as discriminações e as hierarquias sociais efetivamente correspondem a esses marcadores; e, por fim, tais identidades e discriminações são imprescindíveis "em termos tecnológicos, sociais e políticos para a afirmação social dos grupos oprimidos”.

Para abordar a identidade étnico-racial, que é o que nos interessa mais diretamente neste artigo, decidimos analisar uma unidade que, em seu tema transversal, trouxe descrito o eixo "Pluralidade Cultural". Neste volume 3, tanto a unidade 5 quanto a 6 exploraram este tema transversal. Nós selecionamos a unidade 6 para aprofundar a discussão. Em Jovino (2014), já apontávamos os aspectos interessantes de tais unidades, embora seja possível notar que "negros e negras não aparecem como autores ou como temas dos textos na mesma proporção que são representados 
imageticamente” (p. 136), embora seja numericamente bastante inferior à de brancos.

O título da unidade 6, Diferentes, pero todos bárbaros, já indica que a unidade terá uma preocupação com a temática das diferenças. A imagem da página em que se destaca o título, nos permite concluir que a discussão das diferenças se voltará para as pessoas, ou seja, como os sujeitos são diferentes, mas ao mesmo tempo, que essas diferenças revelam que todos são bárbaros. No que se refere ao adjetivo “bárbaro”, a princípio, podemos ser conduzidos a dois significados, um mais positivo e outro mais negativo. No decorrer da unidade, esse adjetivo vai ser debatido em diferentes atividades e o significado vai se esclarecendo.

Os textos que compõem a unidade didática podem ser resumidos a 14. Todos eles são textos autênticos, sendo que 12 foram retirados de sites de internet, um foi retirado de um discurso na ONU, e dez sofreram alguma adaptação. No que se refere ao gênero textual, há quatro biografias de personalidades históricas, há um discurso na ONU, há duas leis, há três músicas, há duas entrevistas, há uma carta e há um poema. Algo importante a respeito desta seleção de gêneros é que esses textos são do Brasil e de diferentes países hispano-falantes, entre eles, Bolívia, Espanha, Argentina, República Dominicana e Porto Rico.

Além disso, a temática dos textos selecionados é muito interessante para a proposta que é lançada na unidade. Já de início, as quatro biografias são apresentadas aos alunos, e se tratam de biografias (p. 94) de dois indígenas (o presidente da Bolívia e um conhecido e respeitado indígena brasileiro) e de dois líderes revolucionários negros (um de Porto Rico e outro do Brasil). Ou seja, a temática das diferenças tem seu debate iniciado abordando indígenas e negros que têm e tiveram importância significativa para a construção da história em seus países. O exercício proposto para explorar essas biografias possibilita aos alunos refletir sobre a ação desses personagens na sociedade e se os ideais pelos quais lutam/lutaram ainda são vigentes na atualidade no Brasil.

Logo em seguida há um exercício de escuta (quinto texto, p. 95), em que se apresenta um gênero oral autêntico, sobre um fragmento do discurso do presidente Evo Morales (anteriormente estudado nas biografias) na ONU. Este exercício de escuta centra o debate na questão indígena e possibilita sua ampliação acerca da identidade indígena nos dias atuais na América hispânica.

Na sequência, a questão da identidade indígena é aprofundada com a apresentação da Lei boliviana (p. 95) que reconhece todos os idiomas das nações e povos indígenas e garante o direito dos alunos de todos os níveis de ensino a receber uma educação intracultural, intercultural e plurilíngue; sendo que, além da língua espanhola, o estudante terá o direito e dever de aprender outro idioma oficial, que seja predominante na região 
onde vive. Assim, a temática da identidade e da língua é posta lado a lado para ser discutida com os alunos. Aproveitando esta questão das línguas e da identidade indígena, há um exercício sobre palavras indígenas que foram incorporadas à língua espanhola e sobre as palavras adequadas para se classificar a origem étnico-racial quando há ou não mistura com povos indígenas.

O que podemos avaliar, nos exercícios que se referem à Lei boliviana e às marcas das culturas indígenas na língua espanhola e nas identidades dos povos falantes de espanhol, é que se objetiva tratar de questões de políticas linguísticas e suas relações com o conceito de identidade. Assim, o estudo da LE se amplia para além de conteúdos estruturais e comunicativos, começa a se voltar para conceitos mais atuais que estão sendo discutidos nos campos da Linguística, Linguística Aplicada e que consideram a participação dos sujeitos nas constituições das línguas.

Após esta introdução à temática indígena na história, na língua e na origem dos povos americanos, o sétimo texto (p. 97) - um trecho de entrevista de um linguista holandês - traz ao debate o conceito de "bárbaro", presente no título da unidade. A partir da leitura deste texto é proposto que os alunos reflitam sobre o racismo nos diferentes momentos históricos, pensando nos grupos dominantes e nos excluídos neste processo. E, logo em seguida, temos a apresentação do oitavo texto (p. 98), um poema com as vozes de um cantor negro e de um homem dos pampas. Este poema vai abordar as diferenças entre brancos e negros. Nos exercícios sobre o poema, a questão étnico-racial é retomada, mas agora focando o negro. Nas atividades finais referentes ao poema (p. 99), um dos versos é destacado porque conteria uma visão relativista do racismo, dando a entender que negros e brancos se discriminariam em nível de igualdade de poder, utilizando-se de um mesmo discurso, invertendo-se apenas os termos ou sua ordem. A última atividade inclui mais um trecho da entrevista do linguista holandês Teun van Dijk, que fala da relação entre discurso e poder, e solicita que os estudantes discutam a respeito.

O nono texto (p. 102) consiste numa canção que vai gerar a proposta de uma atividade para que o aluno se coloque no lugar do outro para resolver algumas situações. Novamente há uma preocupação de que o aluno reflita sobre o outro, que é diferente dele, e questões de identidade. Na sequência, para abordar as expresiones concesivas, se apresenta o décimo texto (p. 103), uma entrevista com uma descendente mapuche, povo indígena mais numeroso no Chile. Neste caso, o que podemos constatar é que, mesmo quando há conteúdos mais gramaticais na unidade, podemos identificar um intento de continuar explorando a reflexão dos alunos acerca das identidades, sejam elas de origem indígena ou africana.

Na análise do gênero textual, que é organizada na seção En otras palabras, temos o décimo primeiro texto (p. 105), a carta de uma 
representante de uma fundação que trata dos direitos dos ciganos. Mais uma vez a questão das etnias é tratada na unidade, mostrando que na Espanha há ciganos e que a nação espanhola também pode ser formada por diferentes povos. Esta atividade, ainda, explica a função da carta, sua estruturação e alguns aspectos da estrutura composicional (argumentos, conectores, uso de pontuação) para exemplificar e, em seguida, a proposta de produção é apresentada. Nesta produção, os alunos deverão escrever uma carta a algum diretor de meio de comunicação para expressar seu ponto de vista a respeito de alguma ação que lhe tenha parecido discriminatória. Assim, além do aluno refletir sobre a função da mídia no cuidado com o tratamento de mensagens, imagens, etc., preconceituosas e racistas, ele tem a oportunidade de expressar sua opinião a respeito de alguma ação discriminatória que tenha identificado nos veículos de comunicação.

O décimo segundo texto (p. 106) é a tradução de uma Lei brasileira para o espanhol. Esta Lei garante a reserva de 50\% das matrículas para alunos das escolas públicas nos institutos federais, sendo que estes alunos serão subdivididos de acordo com a renda familiar, o percentual de negros, pardos e indígenas. A partir deste texto é organizada uma atividade de debate na sala. Novamente se constata uma preocupação em tratar de aspectos de identidade relacionados a questões políticas, motivando o aluno a refletir e se posicionar sobre o tema.

Por fim, os décimo terceiro e quarto textos (p. 107) são duas músicas, uma em língua portuguesa e outra em língua espanhola, que aparecem juntas na seção Nos... otros. Primeiramente, há a apresentação de três atividades, sendo que a terceira delas se refere mais diretamente às músicas. Nas duas primeiras atividades há uma proposição de discussão sobre os conceitos de racismo, racista e racismo cordial, levando o aluno a refletir mais uma vez sobre o caráter social e histórico desses conceitos. No último exercício, os alunos precisam avaliar se as músicas apresentadas trazem conteúdo discriminatório e justificar esta avaliação.

A partir da análise dos textos e atividades propostas, concluímos que há um cuidado com a seleção de textos autênticos, de fontes e de países diversos, para promover o estudo, a reflexão e o debate acerca das identidades raciais e da diversidade cultural. Nesta unidade 6, especificamente, os textos se voltam para as identidades dos indígenas e dos negros na América hispânica, mas também há um momento em que se aborda a identidade cigana no contexto espanhol.

Além disso, é possível constatar uma preocupação em conectar uma atividade com a outra, ou seja, não há atividades que ficam perdidas e sem função na construção da unidade; pelo contrário, elas estão organizadas em uma sequência que permite um aprofundamento sobre o racismo, a discriminação, as identidades e as políticas linguísticas, de maneira que o aluno possa conduzir seu estudo da língua sem desvencilhá-lo destas questões. 
De maneira geral, podemos verificar que há uma grande quantidade de textos na unidade didática analisada. Essa quantidade de textos pode, a princípio, parecer excessiva para se trabalhar com estudantes de EM; no entanto, avaliamos que, do modo que os textos são tratados e como são utilizados para propor atividades, provavelmente não se tornarão maçantes para o público-alvo deste LD. Pelo contrário, são textos que possibilitarão uma interação dos alunos entre si, com a professora e a inserção de temáticas que são polêmicas e precisam ser debatidas no contexto atual, uma vez que a necessidade de se superar o racismo e ações discriminatórias, seja para com o brasileiro ou em relação ao estrangeiro, é urgente. E não se trata somente da superação de ações discriminatórias mas também da construção de uma visão de mundo diferenciada, em que os povos são compreendidos e valorizados na sua heterogeneidade e diversidades.

\section{Considerações finais: reatando laços}

A análise da Coleção Enlaces não foi feita em sua completude neste artigo. Detivemo-nos em uma das unidades do volume 3. Nesse sentido, não podemos avaliar como toda a coleção trabalha a temática da identidade racial no ensino da língua espanhola. No entanto, pela análise da unidade 6, conseguimos apontar alguns aspectos que são importantes para o contexto do ensino da língua espanhola na atualidade e para as pesquisas na área dos LDs.

Um dos pontos essenciais que nos chamou a atenção foi a seleção dos textos para compor a unidade. Todos eles são textos autênticos e provenientes de diversas fontes e países falantes da língua espanhola. Os textos em si, portanto, já revelam uma diversidade para tratar o espanhol. Além disso, o próprio título da unidade indica uma ampliação tanto temática quanto conceitual para tratar o ensino de espanhol. Em termos de temática, verificamos quase que um ineditismo no que se refere ao estudo das questões de identidade e políticas linguísticas para o contexto de E/LE no EM. Em termos de conteúdo, podemos verificar que a compreensão do estudo da língua não é desvinculado do estudo de aspectos culturais, históricos, políticos, identitários, etc., ou seja, o conceito de língua é ampliado neste LD.

Outro ponto a se destacar é uma aproximação do LD das bases teóricas e didáticas fundamentais dos documentos oficiais e também de discussões recentes na área da Linguística, da Linguística Aplicada e da Educação a respeito do conceito de língua/linguagem, do estudo da cultura, da identidade e da importância da diversidade nos processos de ensino/ aprendizagem de uma LE. Consideramos que os LDs que chegam para o professor da escola pública são recursos didáticos fundamentais para suas aulas, pois, em muitos casos, representam o único material a que ele e seus 
alunos terão acesso para estudar a LE. Sendo assim, unidades didáticas como a que analisamos da Coleção Enlaces podem contribuir para os processos formativos de cidadãos mais críticos, menos preconceituosos e mais abertos e respeitosos em relação à diversidade.

Também não podemos deixar de destacar o papel político dos movimentos sociais para que tenhamos chegado até aqui. Destacamos pela proximidade temática da pesquisa, a atuação da militância negra, sem desconsiderar os movimentos indígenas e de outros grupos. Guimarães (2008, p. 75) destaca, por exemplo, a importância do Movimento Negro Unificado (MNU) para o questionamento da democracia racial e para o que ele chama de reintrodução da ideia de raça. Ao olhar o passado e reivindicar uma origem africana para os negros brasileiros, o MNU na década de 1970 "introduz de novo a ideia de raça no discurso sobre a nacionalidade brasileira”. Gonçalves e Silva (2003) corroboram o pensado por Silva ao afirmarem que "o nosso olhar sobre esse tema estava profundamente marcado por nossa longa experiência de militância” (p. 112).

É também a militância que tem papel decisivo para o estabelecimento das leis federais que estabelecem a obrigatoriedade do ensino de história e cultura africana, afro-brasileira e indígena. E com isso se pode também acompanhar as mudanças nos editais do PNLD, uma vez que foram sendo modificados e, onde inicialmente havia recomendações de que não se veiculassem preconceitos, o que dava margem para o discurso de silenciamento total sobre os grupos minoritários, como negros e indígenas, pode-se ver hoje explicitamente nos critérios de avaliação das obras que se deve considerar a "abordagem de temas abrangentes e contemporâneos, que contemplem diferentes dimensões da vida humana, tanto na esfera individual, quanto global, regional e local” (PNLD, 2013, p. 27).

Dessa forma, indicam as diretrizes de avaliação que os livros precisam "representar a sociedade” e devem buscar:

[...] promover positivamente a imagem de afro-descendentes e descendentes das etnias indígenas brasileiras, considerando sua participação em diferentes trabalhos, profissões e espaços de poder; - promover positivamente a cultura afro-brasileira e dos povos indígenas brasileiros, dando visibilidade aos seus valores, tradições, organizações e saberes sociocientíficos, considerando seus direitos e sua participação em diferentes processos históricos que marcaram a construção do Brasil, valorizando o caráter multicultural da nossa sociedade; - abordar a temática das relações étnico-raciais, do preconceito, da discriminação racial e da violência correlata, visando à construção de uma sociedade antirracista, solidária, justa e igualitária. (PNLD, 2013, p. 27).

Ao falar de promoção positiva da imagem, o PNLD nos faz retomar, para finalizar, a questão da representação. Os discursos anunciados pelo LD adentram, de algum modo, no imaginário social, tecendo os estereótipos que 
moldam e fixam concepções que nos informam de maneira generalizada um perfil sobre um determinado grupo. Por isso nós nos apoiamos nos estudos culturais para compreender o papel da representação e sua ligação com a identidade, para que possamos continuar a problematizar a questão nos discursos e no campo social.

\section{Referências}

BARROS, J.; SANTOS, M. A (re)construção de identidades sociais nos livros didáticos de língua estrangeira: por uma pedagogia radical. In: ENCONTRO DO CÍRCULO DE ESTUDOS LINGUÍSTICOS DO SUL, 10, 2012, Cascavel. Anais do CELSUL. Cascavel: CELSUL, 2012. Disponível em: <//www.celsul.org.br/Encontros/10/completos/xcelsul_ artigo\%20(99).pdf $>$. Acesso em: maio 2014.

. Investigando identidades sociais de gênero no livro didático de espanhol por meio da análise crítica do discurso. In: FERREIRA, A. de J. (Org.). As políticas do livro didático e identidades sociais de raça, gênero, sexualidade e classe em livros didáticos. Campinas, SP: Pontes Editores, 2014. p. 185-204.

BRASIL. Secretaria de Educação Fundamental. Parâmetros Curriculares Nacionais: terceiro e quarto ciclos: apresentação dos temas transversais. Brasília: MEC/SEF, 1998.

- Parâmetros Curriculares Nacionais para o Ensino Médio. Brasília: Ministério da Educação, Secretaria de Educação Básica, 2000.

- Secretaria de Educação Média e Tecnológica. PCN+ Ensino Médio: orientações educacionais complementares aos Parâmetros Curriculares Nacionais. Linguagens, Códigos e suas Tecnologias. Brasília: MEC, SEMTEC, 2002.

Lei 10.639/2003. Estabelece a obrigatoriedade do Ensino de História e Cultura Afro-Brasileira e Africana. Brasília, Ministério da Educação, 2003.

Parecer CNE/CP 3/2004. Diretrizes Curriculares para a Educação das Relações Étnico-Raciais e para o Ensino de História e Cultura Afro-Brasileira e Africana. Brasília, Ministério da Educação, 2004.

. Lei 11.161/05. Dispõe sobre o ensino da língua espanhola. Diário Oficial da União, Brasília, n. 151, seção 1, 8 ago. 2005. p. 1.

Orientações Curriculares Nacionais para o Ensino Médio: linguagens, códigos e suas tecnologias. Conhecimentos de Espanhol. Brasília: MEC/Secretaria da Educação Básica, 2006. 
Lei 11.645 de 10 de março de 2008. Altera a Lei no 9.394, de 20 de dezembro de 1996, modificada pela Lei no 10.639, de 9 de janeiro de 2003, que estabelece as diretrizes e bases da educação nacional, para incluir no currículo oficial da rede de ensino a obrigatoriedade da temática "História e Cultura Afro-Brasileira e Indígena”. Diário Oficial da União, Brasília, 11 mar. 2008.

CANDAU, Vera (Org.). Didática: questões contemporâneas. Rio de Janeiro: Forma \& Ação, 2009.

COUTO, L. P.; JOVINO, I. S.; MACIEL, D. T. E. Livro didático de espanhol: a promoção de um ensino na perspectiva dos gêneros textuais e das africanidades. Eutomia, Recife, vol. 1, p. 449-469, 2013.

GONÇALVES, L. A. O.; SILVA, P. B. G. e. O jogo das diferenças, o multiculturalismo e seus conceitos e seus contextos. Belo Horizonte: Autêntica, 1998.

Multiculturalismo e educação: do protesto de rua a propostas e políticas. Educação e Pesquisa, São Paulo, 2003, v. 29, n. 1, p. 109-123.

FERREIRA, A. de J. Identidades sociais de raça, etnia, gênero e sexualidade. Práticas pedagógicas, em sala de aula de línguas e formação de professores/as. Campinas, SP: Pontes Editores, 2012.

FERREIRA, A. de J. (Org.). As políticas do livro didático e identidades sociais de raça, gênero, sexualidade e classe em livros didáticos. Campinas, SP: Pontes Editores, 2014.

. Identidades sociais de raça, gênero, sexualidade e classe nos livros didáticos de língua estrangeira na perspectiva da linguística aplicada. In: FERREIRA, A. de J. (org.). As políticas do livro didático e identidades sociais de raça, gênero, sexualidade e classe em livros didáticos. Campinas, SP: Pontes Editores, 2014. p. 91-120.

GUIMARÃES, A. S. A. Raça, cor e outros conceitos analíticos. In: SANSONE, L.; PINHO, O. A. (Orgs). Raça: novas perspectivas antropológicas. 2. ed. rev. Salvador: Associação Brasileira de Antropologia: EDUFBA, 2008. p. 63-84.

. Classes, raças e democracia. São Paulo: Editora 34, 2002.

HALL. S. El espectáculo del "Outro". In: HALL, Stuart. Sin garantías. Trayectorias y problemáticas en estudios culturales. Popayán-LimaQuito: Envión Editores-IEP- Instituto Pensar-Universidad Andina Simón Bolívar. [1997]. 2010. p. 419-446. Disponível em: < http://www.ram-wan. net/restrepo/hall/el\%20espectaculo\%20del\%20otro.pdf $>$. Acesso em: maio 2014.

JOVINO, I. da S. Representação de negros e negras num livro didático de espanhol: alguns apontamentos. Simpósio Nacional e Internacional 
de Letras e Linguística, 14., 2013, Uberlândia. Anais do XIV SILEL. Uberlândia: XIV SILEL, 2013. Disponível em: <http://www.ileel2.ufu.br/ anaisdosilel/pt/arquivos/silel2013/1714.pdf> . Acesso em: maio 2014.

- Representação de Negros e Negras Num Livro Didático de Espanhol: Alguns Apontamentos. In: FERREIRA, A. de J. (Org.). As políticas do livro didático e identidades sociais de raça, gênero, sexualidade e classe em livros didáticos. Campinas, SP: Pontes Editores, 2014. p. 121-142.

. A teoria dos gêneros textuais na prática e a implementação da Lei 10.639/03. Encontro Nacional de Didática e Prática de Ensino, 14. Anais do XIV ENDIPE. Campinas: Junqueira \& Marin Editores. Livro 2, 2012. p. 24-36.

MUNANGA, K. Uma abordagem conceitual das noções de raça, racismo, identidade e etnia. Cadernos PENESB (Programa de Educação sobre o Negro na Sociedade Brasileira). Rio de Janeiro: UFF, 2003, n. 5, p. 15-34.

OSMAN et al. Enlaces. São Paulo: Macmilan, vol. 3, 2013.

PARANÁ. Diretrizes Curriculares de Língua Estrangeira Moderna. Curitiba: Secretaria de Estado da Educação, 2008.

PARAQUETT, M. Multiculturalismo, interculturalismo e ensino/ aprendizagem de espanhol para brasileiros. IN: BRASIL. Coleção Explorando o Ensino. Espanhol. Brasília: MEC, 2010. vol. 16. p.137292. Disponível em: <http://mec.gov.br>. Acesso em: mar. 2012.

SCHEYERL, D.; SIQUEIRA, S. (Orgs). Materiais didáticos para o ensino de línguas na contemporaneidade: contestações e proposições. Salvador: EDUFBA, 2012.

PROGRAMA NACIONAL DO LIVRO DIDÁTICO. 2011. Brasília: Ministério da Educação. Disponível em:<http://portal.mec.gov.br/index.ph p?Itemid=668\&id=12391\&option=com_ content $\&$ view $=$ article $>$. Acesso em: maio 2012.

PROGRAMA NACIONAL DO LIVRO DIDÁTICO. Brasília: MEC/ SEB/FNDE. 2013. Disponível em: < http://www.fnde.gov.br/arquivos/ category/165-editais?download=5024: pnld-2013-edital.>. Acesso em: ago. 2014.

ROSEMBERG, F., BAZILLI, C.; SILVA, P. V. B. Racismo em livros didáticos brasileiros e seu combate: uma revisão da literatura. 2003. Educação e pesquisa. São Paulo: Universidade de São Paulo, 2003. p.125-146.

SILVA, A. C. da. A discriminação do negro no livro didático. Salvador: Centro Editorial e Didático da UFBA; Centro de Estudos Afro-Orientais, 1995. 
SILVA, P. V. B. da. Relações raciais em livros didáticos de língua portuguesa. Tese (Doutorado em Psicologia Social) São Paulo: Pontifícia Universidade Católica de São Paulo, 2005.

WOODWARD, K. Identidade e diferença: uma introdução teórica e conceitual. In: SILVA, T. T. da. (Org.). Identidade e diferença: a perspectiva dos estudos culturais. Petrópolis, RJ: Vozes, 2000. p. 7-72. 